\title{
Dwarf eelgrass (Zostera noltii) leaf fatty acid profile during a natural restoration process: Physiological and ecological implications
}

\author{
Bernardo Duarte $^{\mathrm{a}, *}$, Ana Rita Matos ${ }^{\mathrm{b}}$, Sílvia Pedro ${ }^{\mathrm{c}}$, João Carlos Marques ${ }^{\mathrm{d}}$, Helena Adão ${ }^{\mathrm{c}}$, \\ Isabel Caçador ${ }^{\mathrm{a}}$ \\ ${ }^{\text {a } M A R E ~-~ M a r i n e ~ a n d ~ E n v i r o n m e n t a l ~ S c i e n c e s ~ C e n t r e, ~ F a c u l t y ~ o f ~ S c i e n c e s ~ o f ~ t h e ~ U n i v e r s i t y ~ o f ~ L i s b o n, ~ C a m p o ~ G r a n d e, ~} 1749-016$ Lisbon, Portugal \\ ${ }^{\mathrm{b}}$ BioISI-Biosystems and Integrative Sciences Institute, Plant Functional Genomics Group, Departamento de Biologia Vegetal, Faculdade de Ciências da Universidade de \\ Lisboa, Campo Grande, 1749-016 Lisboa, Portugal \\ ${ }^{\mathrm{c}}$ MARE - Marine and Environmental Sciences Centre, University of Évora, School of Sciences and Technology, Apartado 94, 7002-554 Évora, Portugal \\ ${ }^{\mathrm{d}}$ MARE - Marine and Environmental Sciences Centre, c/o DCV, Faculty of Sciences and Technology, University of Coimbra, Coimbra, Portugal
}

\section{A R T I C L E I N F O}

\section{Keywords:}

Ecosystem engineers

Essential fatty acids

Seagrass

Restoration

\begin{abstract}
A B S T R A C T
Seagrass beds are among the most relevant ecosystem engineers, providing essential ecosystem services for the surrounding coastal communities. Alongside, these ecosystems are among the most threaten in the world, and thus several restoration projects have been developed in the past years. Seagrasses are important sources of essential fatty acids (FA) for animals, which are unable to synthetize them. During the seagrass growth and photochemical maturation, there is a membrane remodelling, where some fatty acids are synthetized. When analysing the FA changes at different development stages, one of the first noticeable changes is the increase in C16:1t (trans-hexadecenoic acid), associated to an increase in the chloroplast membrane fluidity, essential for the efficient energy transduction processes to occur in the thylakoids. Also, interesting to observe are the high levels of omega-3 and -6 (30-43\% and $18-31 \%$ of total fatty acid content, respectively) present in this seagrass, reinforcing the nutritional value of this species as source of essential fatty acids for the primary consumers. Additionally, it is possible to observe that in the more mature plants there is a high leaf concentration of C18:3. Recent reports suggest that C18:3 can act as a direct scavenger of reactive oxygen species (ROS), indicating a lower stress level, as suggested by the higher photochemical efficiency previously observed. Moreover, it is also interesting to observe that total long-chain polyunsaturated fatty acids (LC-PUFAs) content show a significant increase with the biomass development. These LC-PUFAs are not produced by higher plants and their production in animals occurs at low rates, suggesting they may have as origin the microalgae in the grass surface, adding another important ecosystem service to these prairies, as support for microalgae development and carriers of LCPUFAs into the food web.

This membrane remodelling appears to be on the basis of the photochemical maturation of these seagrasses observed in previous studies and can be used as potential and efficient tool to monitor the development stage of the prairies and its physiological status in future restoration processes. Moreover, it becomes evident that highly developed seagrass beds are crucial food source providers in terms of essential fatty acids to the estuarine heterotrophic life.
\end{abstract}

\section{Introduction}

Alongside with salt marshes and mangroves, seagrass meadows are among the most important coastal ecosystems on the planet (Duarte et al., 2018c). These foundation habitat-forming species influence ecosystem structure and function by creating locally stable conditions for other species (Thomson et al., 2015). Seagrasses are key-players in the marine ecosystem by providing not only shelter and reproduction grounds for several important animal species, but also by being an important food source to the whole food chain, both directly and due to detritus exportation (Duarte et al., 2017b; Repolho et al., 2017). The polyunsaturated fatty acids (PUFAs) linoleic (C18:2, n-6) and $\alpha$-linolenic (C18:3, n-3) are essential fatty acids which cannot be synthetized by animals (van Ginneken et al., 2011). These are precursors of long chain PUFAs (LC-PUFAs) such as arachidonic acid (C20:4, n-6), eicosapentaenoic acid (EPA, C20:5, n-3) and docosahexaenoic acid (DHA, C22:6, n-3) with fundamental with key roles in aquatic animals physiology, including the enhancement of growth rates and reproductive

\footnotetext{
* Corresponding author.
} 
capacities (Elert, 2004). Long chain PUFA and their derivatives are also of great importance to the neural/cognitive, cardiovascular, and visual health of terrestrial vertebrates (Calder, 2015). Additionally, lipids, in the form of triglycerides, are the most effective sources of storage energy, whereas polar lipids play crucial roles as structural constituents of all cellular membranes and are also involved in signalling processes (Singh et al., 2002).

Currently, seagrass meadows are experiencing a rapid and global decline at faster rates than the loss of tropical rain forests (Waycott et al., 2009). While gradual habitat degradation causes gradual diebacks, extreme climate events result in sudden large-scale collapses (Duarte et al., 2018c, 2017b; Moore et al., 2014; Nicastro et al., 2013). Nevertheless, in some cases it is also possible to observe a regrowth and recover of the seagrass beds, after these collapses (Duarte et al., 2018c, 2017b). During seagrass bed formation there is an evident and important metabolic development in terms of primary production allowing a substantial increase in the seagrass bed biomass (Duarte et al., 2017b). It is expected that these metabolic changes are also connected to the seagrass leaf fatty acid profile which in turn is intrinsically connected with the healthy functioning of the photosynthetic apparatus and the plant resilience towards environmental changes (Duarte et al., 2018d, 2017a). Several reports suggest that lipids are involved in the PS II protection against sudden abiotic changes (Sui et al., 2010), which is reflected for example in changes in the content of galactolipids of chloroplast membranes (Müller and Santarius, 1978). Moreover, the unsaturation degree of membrane fatty acids was shown to be a key factor in the protection of photosystem I and II (Allakhverdiev et al., 2001). This reinforces the key role of membrane remodelling during seagrass growth and in the resistance to the constant changes occurring in their highly dynamic habitats (estuarine and coastal areas). Furthermore, the consequences of these biochemical and physiological cascades are also predicted to spread to terrestrial animals due to the flux of aquatic biomass, containing LC-PUFA, which normally passes from aquatic to terrestrial ecosystems (Gladyshev et al., 2013).

Considering the great importance that seagrass beds have for the whole coastal ecosystems, it becomes therefore important to understand how their fatty acid profiles are altered along a developmental gradient and its physiological and ecological implications.

\section{Material and methods}

\subsection{Sample collection}

Sampling was carried out at Mira Estuary in February 2015. The Mira estuary is a small mesotidal system with a semidiurnal tidal regime, located on the south-western coast of Portugal $\left(37^{\circ} 40^{\prime} \mathrm{N}, 8^{\circ} 40^{\prime}\right.$ W). It is formed by a single channel, with 5-10 $\mathrm{m}$ deep and up to $400 \mathrm{~m}$ wide. Saline tide propagates through the channel along $40 \mathrm{~km}$ upstream. Its low seasonal and limited freshwater input, makes the lower section predominantly marine with Zostera noltii meadows, bare sandy areas and muddy substrates, with salt-marshes occurring as far as $20 \mathrm{~km}$ upstream. This estuary is considered relatively undisturbed and free from industrial pollution (Caçador et al., 2013; Costa et al., 2001). This study was conducted at a small mesotidal system in the north bank of this estuary (Fig. 1) that together with the Mira River and its surrounding area is included in the protected Natural Park "Sudoeste Alentejano e Costa Vicentina" (Branco et al., 2018). Four sampling sites (A, B, C and D correspondent to Development Stages 1 to 4) were chosen according to their seagrass coverage (Fig. 1 and Table 1 ) assessed in a first census by visual inspection (Duarte et al., 2017b). Additionally, from this same sampling campaign resulted a previous study that also showed that these patches show increasing degrees of photobiological maturation (Duarte et al., 2018b) (Table 1), as shown by its increasing quantum yield values (Fv/Fm). The 2008 collapse event and the following irregular recovery since 2009 (Materatski et al., 2016), lead to the re-appearance of patches at different developmental

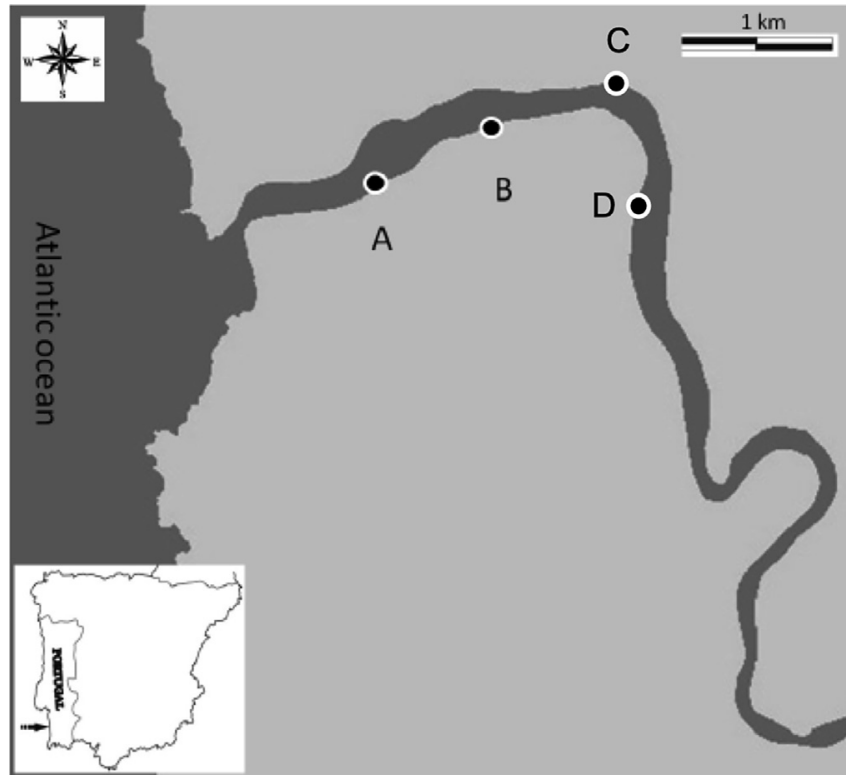

Fig. 1. Mira estuary location and sampled Zostera noltii beds sites.

Table 1

Seagrass development (assessed through its coverage) and photochemical efficiency $(\mathrm{Fv} / \mathrm{Fm})$ in the four sampling sites (average \pm standard deviation, $\mathrm{N}=3$, letters denote statistical differences at $P<0.05$ ).

\begin{tabular}{lllll}
\hline & Stage 1 & Stage 2 & Stage 3 & Stage 4 \\
\hline $\begin{array}{l}\text { Seagrass coverage } \\
(\%)\end{array}$ & $24.9 \pm 0.2$ & $29.4 \pm 0.4$ & $42.2 \pm 0.9$ & $64.1 \pm 0.5$ \\
Fv/Fm & $0.40 \pm 0.05$ & $0.49 \pm 0.06$ & $0.64 \pm 0.04$ & $0.67 \pm 0.02$ \\
\hline
\end{tabular}

stages. The characteristics of this system, included in natural park makes it a perfect one for this kind of studies, due to the reduced effect of anthropogenic disturbance in the seagrass development.

\subsection{Fatty acid analysis}

Leaf fatty acid composition was determined by direct acidic transesterification of pre-weighted leaf portions as previously described (Duarte et al., 2017a; Gameiro et al., 2016). Fatty acid methyl esters (FAME) were separated in a gas chromatograph (3900 Gas Chromatograph, Varian, Palo Alto, CA, USA) equipped with a hydrogen flameionization detector using a fused silica $0.25 \mathrm{~mm}$ i.d. $\times 50 \mathrm{~m}$ capillary column (WCOT Fused Silica, CP-Sil 88 for FAME, Varian) (Feijão et al., 2017). Heptadecanoate (C17:0) was used as an internal standard.

\subsection{Statistical analysis}

Due to the lack of data normality and homogeneity, the statistical analysis of the data was based on non-parametric tests. In order to compare the effects of the tested salt exposures, a Kruskal-Wallis analysis of variance was performed using Statistica Software (Statasoft). Significance was assumed when $P<0.05$. In order to evaluate the changes in the whole fatty acid profile, a multivariate approach was applied (Duarte et al., 2018a, 2019; Laureano et al., 2018; Vidigal et al., 2018). Multivariate statistical analyses were conducted using Primer 6 software (Clarke and Gorley, 2006), using non-parametric multivariate analysis packages. Data regarding the fatty acid relative composition, was used to construct a resemblance matrix based on the Euclidean distances between samples. Canonical Analysis of Principal coordinates (CAP) was used to generate statistical multivariate models based in fatty acid relative composition, and to classify and separate the 

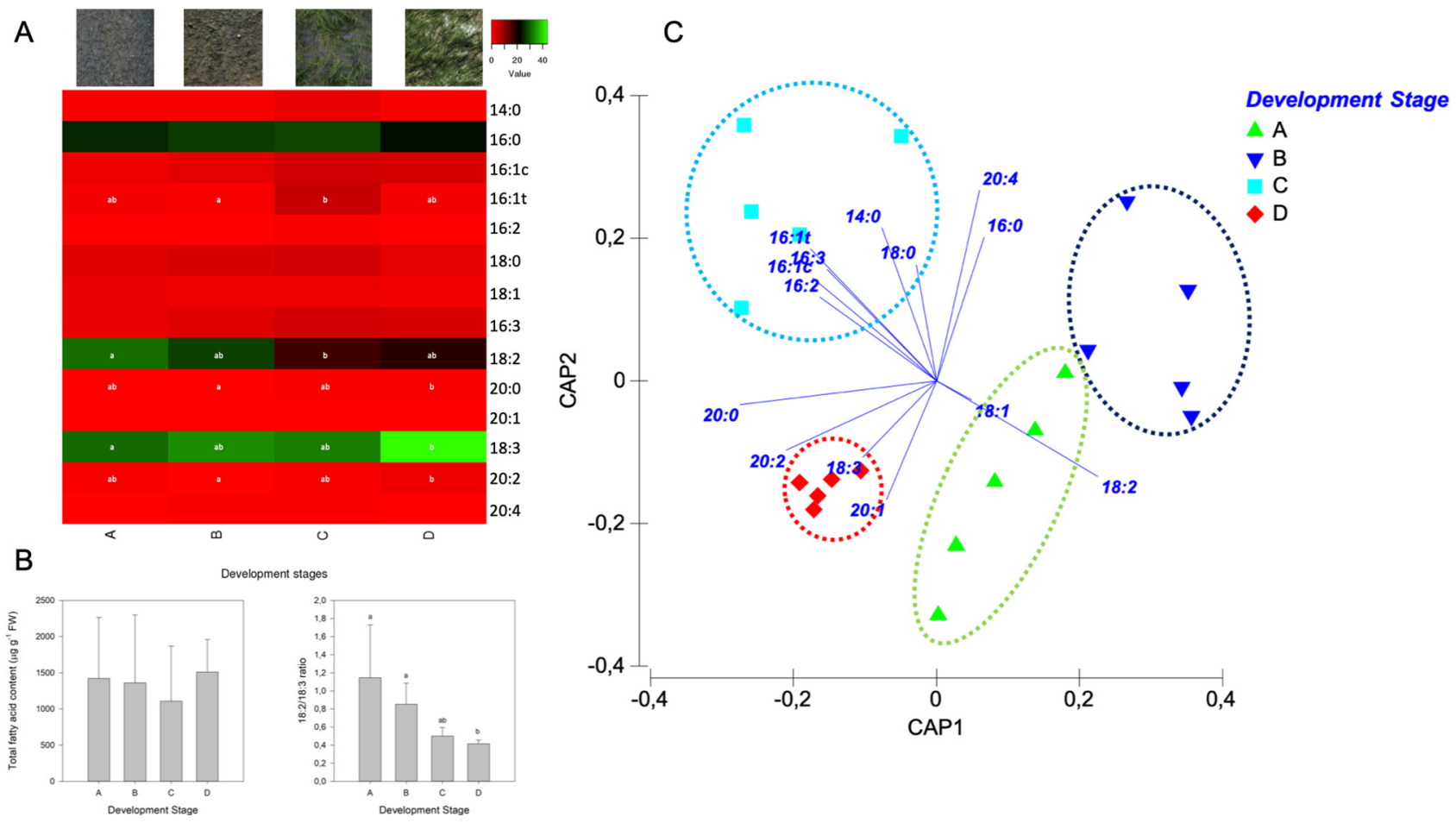

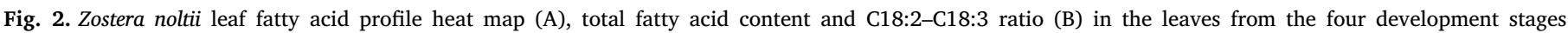

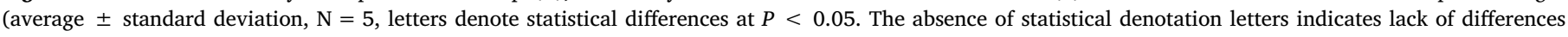

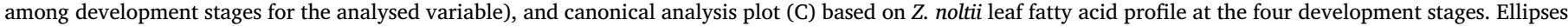
group samples with lower statistical distance.

different treatment groups. This multivariate approach is insensitive to heterogeneous data and frequently used to compare different sample groups using the intrinsic characteristics of each group (metabolic characteristics) (Duarte et al., 2018a, 2019; Laureano et al., 2018; Vidigal et al., 2018).

\section{Results and discussion}

As previously mentioned, the present results are a complement to the work reporting $Z$. noltii development in the same study area and period (Duarte et al., 2017b). In this study, the shoot density and the biomass of $Z$. noltii increased, while its total fatty acid content, on a fresh weight basis, did not change along the developmental gradient (Fig. 2B). This implies that the photochemical maturation previously observed is not due to an increase in the rate of de novo fatty acid synthesis, but most likely to membrane remodelling processes, otherwise an increase in the leaf total fatty acid content would be observed. Analysing the fatty acid profile of $Z$. noltii leaves, it is interesting to observe the presence of small amounts of C16:3 (Fig. 2A). Regarding their fatty acid composition, higher plants are divided in two groups according to the presence or absence of this particular fatty acid. The majority of species are devoid of C16:3 and therefore designated "18:3" plants, while others such as spinach or Arabidopsis thaliana contain significant amounts of C16:3, exclusively in galactolipids present in plastidial membranes, and are called "16:3" plants (Mongrand et al., 1998). Rarer are the so-called intermediary plants which contain very

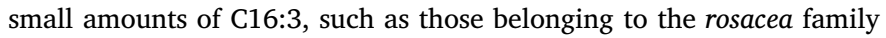
like Pyrus communis (Silvestre et al., 2014) and, according to our results, Z. noltii, with $2-5 \%$ of this fatty acid. When analysing the FA changes at different development stages (Fig. 2A), one of the first noticeable changes is the increase in C16:1t (trans-hexadecenoic acid), throughout the plant development. This fatty acid is generated by a membranebound desaturase acting exclusively on C16:0, esterified to phosphatidylglycerol (PG), which is the only phospholipid present in thylakoids
(Trémolières et al., 1991). Along the development gradient, this fatty acid exhibited a marked increase in its concentration, which could reflect an increase in the abundance of PG and/or be associated to an increase in the chloroplast membrane fluidity, essential for the efficient energy transduction processes to occur in the thylakoids (Duarte et al., 2017a; Trémolières et al., 1991). In agreement, there is also a high correlation between the concentration of the trienoic acid C16:3 and the biomass development $\left(r^{2}=0.70, P<0.05\right)$. Since it is exclusively located in plastidal galactolipids, it corroborates the hypothesis of the increase of plastidial lipids contents, such as mentioned for PG. Moreover, this polyunsaturated fatty acid can also contribute to membrane fluidity. Overall, the increases in C16:1 $t$ and C16:3, which can be used here as chloroplast markers, are in agreement with the increase in the $\mathrm{Fv} / \mathrm{Fm}$ parameter along the developmental stages (Duarte et al., 2017b).

Also, interesting to observe are the high levels of omega-3 (C18:3, $30-43 \%$ of total fatty acid content) and omega- 6 (C18:2, 18-31\% of total fatty acid content) present in this seagrass. Beyond the obvious implications regarding the nutritional value of this species as source of essential fatty acids for the primary consumers, the abundance of linoleic acid (C18:2), when compared to $\alpha$-linolenic acid (C18:3), can also provide important physiological insights. A decrease in the C18:2/ C18:3 ratio (Fig. 2B) favoured by an increase $\alpha$-linolenic acid, has been previously associated with a non-stressful or to a stress alleviation condition (Ben Hamed et al., 2005; Zarrouk and Cherif, 1983). Moreover, recent reports (Mène-Saffrané et al., 2009) suggest that C18:3 can act as a direct scavenger of reactive oxygen species (ROS) which are known to accumulate in plants subjected to salt stress (Duarte et al., 2017a). Under stressful conditions C18:3 can be degraded due to its interaction with ROS, decreasing its content (Duarte et al., 2018d). Here, we observe that in the more mature plants, there is a high concentration of $\mathrm{C} 18: 3$ in the leaves, indicating a lower stress level, as suggested by the higher photochemical efficiency (Fv/Fm). Again, a very strong and positive correlation was found between the C18:3 
relative concentration and the seagrass biomass $\left(\mathrm{r}^{2}=0.93, P<0.05\right)$, while C18:2 exhibited the exact opposite trend $\left(\mathrm{r}^{2}=-0.81\right.$, $P<0.05)$. The increase in C18:3 concentration is normally associated to a decrease in its precursor fatty acid C18:2 and could be associated to an increase in desaturase activity. From the ecological point of view, these fatty acids acquire an extreme importance, since, as abovementioned, they are precursors of LC-PUFAs and are essential for animals which are unable to synthetize them (van Ginneken et al., 2011). Moreover, it is interesting to observe that total long-chain polyunsaturated fatty acids (LC-PUFAs) content, with more than 20 carbons, also show a strong and significant correlation with the biomass development $\left(\mathrm{r}^{2}=0.84, P<0.05\right)$. These LC-PUFAs are not produced by higher plants and their production in animals occurs at low rates. Their presence in the analysed $\mathrm{Z}$. noltii samples results most likely from the presence of microalgae in the grass surface, such as diatoms and dinoflagellates, which are at the basis of the aquatic food chains and possess the enzymatic machinery to produce LC-PUFA (Feijão et al., 2017).

From the Canonical Analysis of Principal components (Fig. 2C), it is evident that the fatty acid profile is characteristic of each developmental stage. In fact, the canonical model generated through this multivariate analysis, has a classification efficiency of $80 \%$ using only the fatty acid profile as categorizers of the development stages. The $50 \%$ of the total error comes from misclassifications between the less developed (A and B) and most mature stages (C and D) where some similarities between the fatty acid profiles can already be found. This points out to an additional role of the fatty acids as potential descriptors of the seagrass developmental stages in future restoration studies.

\section{Conclusion}

The role of seagrasses as ecosystem engineers and as essential service providers for the coastal ecosystems communities, is undeniable. It is also undeniable that these ecosystems are among the most threaten in the world, and thus several seagrass bed restoration projects have been taking place throughout the globe. Throughout a natural and spontaneous restoration process it is possible to understand the metabolic adjustments that these plants suffer during their development in the natural habitat. During its growth, $Z$. noltii suffers a deep membrane remodelling throughout changes in its fatty acid profile, with an important production of PUFAs and LC-PUFAs. These reinforces the importance of these prairies for the whole estuarine and coastal trophic web, by providing these essential molecules, from which the heterotrophic community relies on. Additionally, this membrane remodelling appears to be on the basis of the photochemical maturation of these seagrasses observed in previous studies. Moreover, fatty acid analysis also appears as a powerful tool to assess the development stage of the prairies and its physiological status in future assisted restoration processes.

\section{Acknowledgments}

The authors would like to thank to the "Fundação para a Ciência e Tecnologia (FCT)" for funding the research in the Marine and Environmental Sciences Centre (MARE) throughout the project UID/ MAR/04292/2019 and the Biosystems and Integrative Sciences Institute (BioISI) throughout the project UID/MULTI/04046/2019. B. Duarte investigation was supported by FCT throughout an Investigator Contract (CEECIND/03869/2018). The authors would also like to thank to the PROMAR Program throughout the Project ProMira (PROMAR $\mathrm{N}^{\circ}$ 31-03-02-FEP-006), to the Mar 2020 program through the VALPRAD project (MAR-01.04.02-FEAMP-0007) and to ALT20-03-0145-FEDER029400 .

\section{References}

Allakhverdiev, S.I., Kinoshita, M., Inaba, M., Suzuki, I., Murata, N., 2001. Unsaturated fatty acids in membrane lipids protect the photosynthetic machinery against saltinduced damage in Synechococcus. Plant Physiol. 125, 1842-1853. https://doi.org/ 10.1104/pp.125.4.1842.

Ben Hamed, K., Ben Youssef, N., Ranieri, A., Zarrouk, M., Abdelly, C., 2005. Changes in content and fatty acid profiles of total lipids and sulfolipids in the halophyte Crithmum maritimum under salt stress. J. Plant Physiol. 162, 599-602. https://doi. org/10.1016/j.jplph.2004.11.010.

Branco, J., Pedro, S., Alves, A.S., Ribeiro, C., Materatski, P., Pires, R., Caçador, I., Adão, H., 2018. Natural recovery of Zostera noltii seagrass beds and benthic nematode assemblage responses to physical disturbance caused by traditional harvesting activities. J. Exp. Mar. Biol. Ecol. 502, 191-202. https://doi.org/10.1016/j.jembe.2017. 03.003 .

Caçador, I., Neto, J.M.M., Duarte, B., Barroso, D.V.V., Pinto, M., Marques, J.C.C., 2013. Development of an Angiosperm Quality Assessment Index (AQuA-Index) for ecological quality evaluation of Portuguese water bodies - a multi-metric approach. Ecol. Indic. 25, 141-148. https://doi.org/10.1016/j.ecolind.2012.09.021.

Calder, P.C., 2015. Functional roles of fatty acids and their effects on human health. J. Parenter. Enteral Nutr. 39, 18S-32S. https://doi.org/10.1177/0148607115595980.

Clarke, K.R., Gorley, R.N., 2006. PRIMER v6: user manual/tutorial. Prim. Plymouth UK 192, p. https://doi.org/10.1111/j.1442-9993.1993.tb00438.x.

Costa, M.J., Catarino, F., Bettencourt, A., 2001. The role of salt marshes in the mira estuary (Portugal). Wetlands Ecol. Manage. 9, 121-134. https://doi.org/10.1023/ A:1011193421035.

Duarte, B., Cabrita, M.T., Vidal, T., Pereira, J.L., Pacheco, M., Pereira, P., Canário, J., Gonçalves, F.J.M., Matos, A.R., Rosa, R., Marques, J.C., Caçador, I., Gameiro, C., 2018a. Phytoplankton community-level bio-optical assessment in a naturally mercury contaminated Antarctic ecosystem (Deception Island). Mar. Environ. Res. https://doi. org $/ 10.1016 /$ j.marenvres.2018.07.014.

Duarte, B., Cabrita, M.T.T., Gameiro, C., Matos, A.R.R., Godinho, R., Marques, J.C.C., Caçador, I., 2017a. Disentangling the photochemical salinity tolerance in Aster tripolium L.: connecting biophysical traits with changes in fatty acid composition. Plant Biol. 19, 239-248. https://doi.org/10.1111/plb.12517.

Duarte, B., Carreiras, J., Pérez-Romero, J.A., Mateos-Naranjo, E., Redondo-Gómez, S., Matos, A.R., Marques, J.C., Caçador, I., 2018b. Halophyte fatty acids as biomarkers of anthropogenic-driven contamination in Mediterranean marshes: sentinel species survey and development of an integrated biomarker response (IBR) index. Ecol. Indic. 87, 86-96. https://doi.org/10.1016/j.ecolind.2017.12.050.

Duarte, B., Martins, I., Rosa, R., Matos, A.R., Roleda, M.Y., Reusch, T.B.H., Engelen, A.H., Serrão, E.A., Pearson, G.A., Marques, J.C., Caçador, I., Duarte, C.M., Jueterbock, A., 2018c. Climate change impacts on seagrass meadows and macroalgal forests: an integrative perspective on acclimation and adaptation potential. Front. Mar. Sci. 5. https://doi.org/10.3389/fmars.2018.00190.

Duarte, B., Matos, A.R., Marques, J.C., Caçador, I., 2018d. Leaf fatty acid remodeling in the salt-excreting halophytic grass Spartina patens along a salinity gradient. Plant Physiol. Biochem. 124, 112-116. https://doi.org/10.1016/j.plaphy.2018.01.007.

Duarte, B., Pedro, S., Marques, J.C., Adão, H., Caçador, I., 2017b. Zostera noltii development probing using chlorophyll a transient analysis (JIP-test) under field conditions: Integrating physiological insights into a photochemical stress index. Ecol. Indic. 76. https://doi.org/10.1016/j.ecolind.2017.01.023.

Duarte, B., Prata, D., Matos, A.R., Cabrita, M.T., Caçador, I., Marques, J.C., Cabral, H.N., Reis-Santos, P., Fonseca, V.F., 2019. Ecotoxicity of the lipid-lowering drug bezafibrate on the bioenergetics and lipid metabolism of the diatom Phaeodactylum tricornutum. Sci. Total Environ. 650, 2085-2094. https://doi.org/10.1016/j.scitotenv. 2018.09.354.

Elert, E.Von, 2004. Food quality constraints in Daphnia: interspecific differences in the response to the absence of a long chain polyunsaturated fatty acid in the food source. Hydrobiologia 3, 187-196.

Feijão, E., Gameiro, C., Franzitta, M., Duarte, B., Caçador, I., Cabrita, M.T., Matos, A.R., 2017. Heat wave impacts on the model diatom Phaeodactylum tricornutum: searching for photochemical and fatty acid biomarkers of thermal stress. Ecol. Indic. https:// doi.org/10.1016/j.ecolind.2017.07.058.

Gameiro, C., Utkin, A.B., Cartaxana, P., da Silva, J.M., Matos, A.R., 2016. The use of laser induced chlorophyll fluorescence (LIF) as a fast and non-destructive method to investigate water deficit in Arabidopsis. Agric. Water Manage. 164, 127-136. https:// doi.org/10.1016/j.agwat.2015.09.008.

Gladyshev, M.I., Sushchik, N.N., Makhutova, O.N., 2013. Production of EPA and DHA in aquatic ecosystems and their transfer to the land. Prostaglandins Other Lipid Mediat. 107, 117-126. https://doi.org/10.1016/j.prostaglandins.2013.03.002.

Laureano, G., Figueiredo, J., Cavaco, A.R., Duarte, B., Caçador, I., Malhó, R., Sousa Silva, M., Matos, A.R., Figueiredo, A., 2018. The interplay between membrane lipids and phospholipase A family members in grapevine resistance against Plasmopara viticola. Sci. Rep. 8, 1-15. https://doi.org/10.1038/s41598-018-32559-z.

Materatski, P., Vafeiadou, A.M., Moens, T., Adão, H., 2016. Structural and functional composition of benthic nematode assemblages during a natural recovery process of Zostera noltii seagrass beds. Estuaries Coasts 39, 1478-1490. https://doi.org/10. 1007/s12237-016-0086-0.

Mène-Saffrané, L., Dubugnon, L., Chételat, A., Stolz, S., Gouhier-Darimont, C., Farmer, E.E., 2009. Nonenzymatic oxidation of trienoic fatty acids contributes to reactive oxygen species management in arabidopsis. J. Biol. Chem. 284, 1702-1708. https:// doi.org/10.1074/jbc.M807114200.

Mongrand, S., Bessoule, J.J., Cabantous, F., Cassagne, C., 1998. The C16-3/C18-3 fattyacid balance in photosynthetic tissues from 468 plant species. Phytochemistry 49, 
1049-1064.

Moore, K.A., Shields, E.C., Parrish, D.B., 2014. Impacts of varying estuarine temperature and light conditions on Zostera marina (Eelgrass) and its interactions with Ruppia maritima (Widgeongrass). Estuaries Coasts 37, 20-30. https://doi.org/10.1007/ s12237-013-9667-3.

Müller, M., Santarius, K.A., 1978. Changes in chloroplast membrane lipids during adaptation of barley to extreme salinity. Plant Physiol. 62, 326-329.

Nicastro, K.R., Zardi, G.I., Teixeira, S., Neiva, J., Serrão, E.A., Pearson, G.A., 2013. Shift happens: trailing edge contraction associated with recent warming trends threatens a distinct genetic lineage in the marine macroalga Fucus vesiculosus. BMC Biol. 11, 6. https://doi.org/10.1186/1741-7007-11-6.

Repolho, T., Duarte, B., Dionísio, G., Paula, J.R., Lopes, A.R., Rosa, I.C., Grilo, T.F., Caçador, I., Calado, R., Rosa, R., 2017. Seagrass ecophysiological performance under ocean warming and acidification. Sci. Rep. 7. https://doi.org/10.1038/srep41443.

Silvestre, S., Leão de Sousa, M., Ribeiro, D., Rodrigues, B., Pires, S., Matos, A.R., Arrabaça, J.D., Marques da Silva, J., Bernardes da Silva, A., 2014. Pêra "Rocha" do Oeste em pomares com sistema integrado de rega de precisão: variação sazonal de parâmetros fisiológicos e bioquímicos. Proc. $3^{\circ}$ Simpósio Nacional de Fruticultura. Trás os Montes, Portugal. https://doi.org/10.13140/RG.2.1.5074.7608.

Singh, S.C., Sinha, R.P., Häder, D., 2002. Role of lipids and fatty acids in stress tolerance in cyanobacteria. Acta Protozool. 41, 297-308 https://doi.org/citeulike-articleid:3906403.

Sui, N., Li, M., Li, K., Song, J., Wang, B.S., 2010. Increase in unsaturated fatty acids in membrane lipids of Suaeda salsa L. enhances protection of photosystem II under high salinity. Photosynthetica 48, 623-629. https://doi.org/10.1007/s11099-010-0080-x.
Thomson, J.A., Burkholder, D.A., Heithaus, M.R., Fourqurean, J.W., Fraser, M.W., Statton, J., Kendrick, G.A., 2015. Extreme temperatures, foundation species, and abrupt ecosystem change: an example from an iconic seagrass ecosystem. Global Change Biol. 21, 1463-1474. https://doi.org/10.1111/gcb.12694.

Trémolières, A., Roche, O., Dubertret, G., Guyon, D., Garnier, J., 1991. Restoration of thylakoid appression by $\Delta 3$-trans-hexadecenoic acid-containing phosphatidylglycerol in a mutant of Chlamydomonas reinhardtii. Relationships with the regulation of excitation energy distribution. BBA - Bioenergy 1059, 286-292. https://doi.org/10. 1016/S0005-2728(05)80214-2.

van Ginneken, V.J., Helsper, J.P., de Visser, W., van Keulen, H., Brandenburg, W.A., 2011. Polyunsaturated fatty acids in various macroalgal species from north Atlantic and tropical seas. Lipids Health Dis. 10, 104. https://doi.org/10.1186/1476-511X-10104.

Vidigal, P., Duarte, B., Cavaco, A.R., Caçador, I., Figueiredo, A., Matos, A.R., Viegas, W., Monteiro, F., 2018. Preliminary diversity assessment of an undervalued tropical bean (Lablab purpureus (L.) Sweet) through fatty acid profiling. Plant Physiol. Biochem. 132, 508-514. https://doi.org/10.1016/j.plaphy.2018.10.001.

Waycott, M., Duarte, C.M., Carruthers, T.J.B., Orth, R.J., Dennison, W.C., Olyarnik, S., Calladine, A., Fourqurean, J.W., Heck, K.L., Hughes, A.R., Kendrick, G.A., Kenworthy, W.J., Short, F.T., Williams, S.L., 2009. Accelerating loss of seagrasses across the globe threatens coastal ecosystems. Proc. Natl. Acad. Sci. 106, 12377-12381. https://doi.org/10.1073/pnas.0905620106.

Zarrouk, M., Cherif, A., 1983. Lipid contents of halophytic plants and salt-resistance. Z. Pflanzenphysiol. 112, 372-380. 